\title{
Knowledge Infrastructures: Part II
}

\author{
Helena Karasti \\ Department of People and Technology, Roskilde University, Denmark / hkarasti@ruc.dk \\ Information Systems, Luleå University of Technology, Sweden / helena.karasti@ltu.se \\ INTERACT, University of Oulu, Finland / helena.karasti@oulu.fi
}

\author{
Florence Millerand \\ Department of Public and Social Communication, University of Quebec at Montreal, Canada I \\ millerand.florence@uqam.ca
}

\section{Christine M. Hine}

Department of Sociology, University of Surrey, UK / c.hine@surrey.ac.uk

\author{
Geoffrey C. Bowker \\ Department of Informatics, University of Irvine, CA, USA / gbowker@uci.edu
}

The papers presented here were submitted in response to a call for papers that sought to draw together the current state of understanding of knowledge infrastructures from the viewpoint of STS and to provide a basis from which to evaluate the distinctive contribution that the theoretical resources of STS were making within this territory. That call for papers produced a high level of response, providing a clear indication that STS scholars are indeed taking knowledge infrastructures seriously, and that the study of infrastructures is providing fruitful ground for developing insights into STS's core concerns with interrogating the complex, emergent sociotechnical systems that pervade the contemporary world. The initial call for papers produced more successful submissions than could be accommodated in a single issue of the journal, and hence the envisaged special issue will, in fact, extend across multiple issues of which this is the second.

In the previous issue of Science \& Technology Studies, we presented an initial batch of three substantively very different studies: Wyatt et al. (2016) explored the treatment of controversy within the production of the Wikipedia entry relating to schizophrenia genetics; Parmiggiani and Monteiro (2016) examined the production of infrastructures relating to the monitoring of environmental risk in offshore oil and gas operations; and Boyce (2016) analysed the work of connecting infrastructures for public health surveillance. Despite the differing substantive foci we were able to draw out some significant cross-cutting themes. The issue of scale received considerable attention, as the papers each explored what were on the face of it large scale infrastructures but 
were sustained by contingent connections forged across macro-level visions of possible outcomes and diverse forms of micro-level work developing technologies, connecting systems, generating content, overcoming obstacles and managing breakdowns. Our editorial (Karasti et al., 2016) took a reflexive turn, considering the significance of the methodological choices that underpinned these studies of infrastructures and the intransigence of some aspects of infrastructure in the face of our attempts to comprehend them. We noted that the choice of where and how to study such infrastructures involves some significant decisions on the part of the analyst in terms of the focus and level of examination (Larkin, 2013) and also the individual sites and relations to study when a large scale infrastructure can appear at first sight to be everywhere at once and yet nowhere in particular. While the choice to adopt the infrastructural inversion (Bowker, 1994) positions the infrastructure in the foreground and focuses attention on the many forms of work that bring into being and sustain the infrastructure, this initial methodological choice leaves many others for the analyst to navigate.

A further theme that resonated through the articles was the issue of invisibility, whether that concerns the taken-for-granted nature of the infrastructures themselves or the habitual lack of attention in many public spaces to the various forms of work that sustain them. Invisibility has been a fundamental concept within STS studies of infrastructure (e.g. Star \& Ruhleder, 1996; Star, 1999; Bowker \& Star, 1999) and within this batch of papers the notion of invisible work was clearly apparent, and yet across the three papers invisibility played out in quite different ways for both actors in the setting and analysts. Issues of tension, friction and repair also recurred across all three papers, as did the management of ambiguity and uncertainty. Actors and STS analysts sometimes shared a concern with how far to tolerate ambiguity and where to strive for a more concrete solution. Specific relations of accountability determine what counts as a "good enough" knowledge infrastructure for purpose and underpin the accounts that both actors within the setting and their STS guests offer up.
These emergent themes of scale, invisibility, tension, uncertainty and accountability continue to resonate across the four pieces presented in this second instalment of the special issue on knowledge infrastructures. In the rest of this editorial we will introduce the pieces and then draw together, briefly at this point, additional themes that emerge at this stage. In a future editorial we will step back to review these themes across the full collection of papers in order to evaluate the current state and emerging challenges for STS studies of knowledge infrastructure as represented here.

\section{Articles in This Second Part of the Special Issue}

Three articles and one discussion piece are presented in this second part of the special issue. The special issue opens with an article by Masato Fukushima on value oscillation in knowledge infrastructures. By 'value oscillation', Fukushima is referring to the constant to and fro in knowledge infrastructures in the making between participants being told high of the potential positive value of the infrastructural work (for the good it will do in the world) and being warned of its potential negative value (for the harm it can do to one's career to perform service work). The oscillation refers to the constant tacking back and forth between the two. He explores this in two case studies - one of an open database and data library of natural products, and the other of a database used in a drug discovery pipeline. Wrapping these rich empirical analyses is a theoretical argument about linkages that science studies scholars might make with earlier work (notably Marx, Godelier and Lévi-Strauss) through recognizing the resonance with their uses of versions of infrastructure and superstructure. He argues that in a sense we have to our detriment lost touch with our own invisible intellectual infrastructure.

The concept of value oscillation is a particularly good one for understanding knowledge infrastructures in general. From the science studies tradition, particularly actor-network theory, there has been a tendency to see people as either translating the interests of others or having their own interests translated - so that ultimately the black 
box that emerges is unary and univocal. Fukushima's analysis suggests that at different moments one can switch between different value systems without necessarily realizing the contradiction the value, one might say, inheres to the specific situation, not to a single actant. This move opens the possibility for new understandings of the distribution of moral qualities in dense networks of humans and non-humans.

The second paper "Building knowledge infrastructures for empowerment: A study of grassroots water monitoring networks in the Marcellus Shale" focuses on the issues of power and empowerment in the building of knowledge infrastructures for citizen science. Kirk Jalbert studies nongovernmental environmental monitoring networks engaged in water monitoring in a Northeast U.S. area where oil and gas are drilled using hydraulic fracturing, a controversial method of extraction. Jalbert reasons that the lack of transparency in the poorly regulated practice of hydraulic fracturing has made it a particularly germane domain for civil society sector involvement. Citizens become active in attempts to understand the environmental impacts of the oil and gas business in their own backyards.

Jalbert has studied longitudinally two grassroots environmental monitoring networks of citizens. One of them is a coalition of advocacy groups and the second is a large network managed by academic institutions. The networks, concerned for public heath and environmental risks introduced by shale oil and gas extraction, assemble resources for monitoring, collect data and build alliances. They, according to Jalbert's argument, construct distinct knowledge infrastructures that can empower participants to question scientific assessments made by more powerful institutions, participate in public debates and influence regulatory decision-making.

With focus on a discourse of power and empowerment, Jalbert's paper offers a theoretical contribution to facilitate understanding of the conditions under which marginalized stakeholder groups take part in shaping knowledge work and building knowledge infrastructures in order to address complex scientific and environmental issues. Aligning with current understanding of knowledge infrastructures as emerging and adaptable, Jalbert finds that while the formation of knowledge infrastructures can reproduce established relations of power, the grassroots groups are able also to tactically alter power dynamics and redistribute resources to their advantage. This is an encouraging finding for the participation of and influence by marginalized stakeholder groups in the face of the continuing struggles involved in dealing with environmental problems and associated policy struggles as laid out in the conclusions of the paper.

The third paper "Making knowledge in boundary infrastructures: Inside and beyond a database for rare diseases" investigates the ways in which infrastructural issues come to matter in the production of knowledge in the social worlds of rare diseases. Eric Dagiral and Ashveen Peerbaye conducted a four-year ethnography of the "Rare Diseases Platform", a European-level entity created in the early 2000s and located in Paris (France). They analyzed in detail a relational database devoted to rare diseases and orphan drugs that represented one of the major achievements of the large and complex network of individuals, institutions, and practices that the European Platform created.

Their study takes up the concept of "boundary infrastructure" and explores its practical and theoretical implications, by examining how a wide array of actors negotiate the place and forms of knowledge production in relation to many of the other goals they pursue. Indeed, in contrast to situations in which knowledge production is the core legitimate focus of the collective action (e.g. in laboratories or scientific collaboration networks), the involvement of actors and communities around the database for rare diseases extends well beyond this purpose, so that, knowledge production, as one of many outputs of infrastructural work, needs to be articulated with other matters of concern, some with explicit political and moral aspects.

Dagiral and Peerbaye's contribution suggests two main claims. One is the political nature of the distinction between knowledge and 'mere' information, as this demarcation line may embed competing visions on what the infrastructure should be and what it should do in relation to the collectives involved (e.g. researchers, patients, the 
general public, institutions). In looking at the ways in which what counted as knowledge infrastructure and what counted in a knowledge infrastructure was materially enacted within the database, the authors found that the category 'information' rather than 'knowledge' became the category of choice, under which participants in the Platform could frame themselves as involved in the "fight against ignorance of rare diseases", as much as in the production of "novel biomedical knowledge". A second claim recognizes that "infrastructural inversion", this STS methodological lens for the analyst to scrutinize all the activities that warrant the functioning of an infrastructure rather than those that it invisibly supports, may also be constitutive of the practices of the actors themselves. In this case practicing infrastructural inversion served the communities involved to articulate knowledge production with other forms of mobilization, as they negotiated the political, moral and epistemic dimensions of the boundary infrastructure they contribute to. In doing so, the database became reshaped and reconfigured, for instance through classification activities (e.g. choice or deletion of heading for diseases names that didn't "sound right" or that seemed too "complicated" for the patients), thus presenting itself in a state of continued reconfiguration.

In the discussion piece, Kalpana Shankar, Kristin Eschenfelder and Greg Downey use the lens of knowledge infrastructures to shed new light on some well-established practices in their discussion paper "Studying the History of Social Science Data Archives as Knowledge Infrastructure". Social science data archives have been in existence for decades and yet, the authors argue, their role in the development of social science disciplines has been little acknowledged. They suggest that there has been minimal critical attention to the precise nature of the unfolding relationships that constitute social science data archives as infrastructures and in turn shape the possible future directions of the disciplines. Intriguingly, social science data archives pre-date the current era of open access and digital data and provide, the authors argue, for some interesting comparisons with contemporary cyberinfrastructures. Shankar et al. observe early shifts towards data intensive forms of work in social science disciplines that prompt intriguing comparison with contemporary developments. Some interesting international dynamics also emerge, as social science data archives are developed on both sides of the Atlantic and fit themselves into the distinctive arrangements of professional organizations, governmental expectations and funding prospects within each context.

Focusing particularly on quantitative social science data archives, Shankar et al. describe a complex ongoing evolution and mutual shaping of archives and fields of knowledge production, with shifting rationales and sets of relations and an ongoing struggle to justify the labour needed maintain an archive in the face of competing pressures. They suggest that dealing with rupture, discontinuity and breakdown is inherent in the work of infrastructuring, as much as building, creating and forming relationships. Studying the history of social science data archives through the conceptual apparatus offered by STS approaches to infrastructuring provides, the authors suggest, an interesting case to compare with contemporary efforts in other disciplines when considering what makes for a sustainable knowledge infrastructure.

\section{Reflections and Emerging Themes}

Three major commonalities emerge across this rich set of material. The first of these is methodological: each in its own way is performing an act of infrastructural inversion. The authors are looking at what happens when you focus your attention on the infrastructure itself, acknowledging that it has a history and a context and that it takes work to bring it to life. The second common theme flows from the methodological commitment. In their different ways, these articles demonstrate how knowledge infrastructures are performative of the knowledge being produced - they are not passive backdrops. The work of Shankar et al. on the social science archive is interesting for this reason as your theories depend on the kind of archive you can build. Thus for the longest time, ecology as a discipline was tied to its archive of one meter squared plots of land or memory studies to its archive of laboratory results (preventing, in the latter case, the development of social theories of 
memory). Or, in the case of Dagiral and Peerbaye, the 'background' database conjures knowledge into particular forms. The third theme is a development of this perspective: both in their shaping and deployment, knowledge infrastructures are core sites of political action - from the need to represent and acknowledge invisible work to the need to build infrastructures which are sensitive to multiple perspectives. In addition to the concerns with scale, invisibility, tension, uncertainty and accountability identified within the first batch of articles, this issue focuses our attention particularly on concerns with power, marginalization and values. Fukushima highlights the shifting territory of values in relation to infrastructural work and outlines a set of theoretical resources that could bring to the fore a new sensitivity and nuance to the notion of infrastructures as a site of power. Jalbert focuses on discourses of empowerment and the struggles over the potential for marginalization that pervade citizen involvement in infrastructures enabling grassroots environmental monitoring. Dagiral and Peerbaye follow the articulation of infrastructural work with matters of political and moral concern, finding that the distinction between knowledge and information can be highly charged and consequential within struggles to meet the needs of the various collectives implicated in the development of databases depicting rare diseases.

Across these three articles, then, we encounter struggles over power, values and voice at the very heart of infrastructural work. Such concerns are less immediately apparent in the discussion paper from Shankar et al., but are nonetheless present. In setting an agenda for STS-inflected study of social science data archives the authors make clear that these archives too act as sites for negotiation of power, voice and values. Social science data archives, for Shankar et al., become sites where competing versions of the value of different forms of labour and knowledge production collide, where a political will to perform particular kinds of governance and foster certain institutional arrangements is enacted and where visions to move whole academic disciplines towards an envisioned data intensive future play out.

\section{Bibliography}

Bowker GC (1994) Science on the run: Information management and industrial geophysics at Schlumberger, 1920-1940. Cambridge: MIT Press.

Bowker GC \& Star SL (1999) Sorting Things Out: Classification and Its Consequences. Cambridge: MIT Press.

Boyce AM (2016) Outbreaks and the management of'second-order friction': Repurposing materials and data from the health care and food systems for public health surveillance. Science \& Technology Studies 29(1): 52-69.

Karasti H, Millerand, F Hine CM \& Bowker GC (2016) Knowledge infrastructures: Part I. Science \& Technology Studies 29(1): 2-12.

Larkin B (2013) The politics and poetics of infrastructure. Annual Review of Anthropology 42: 327-343.

Parmiggiani E \& Monteiro E (2016) A measure of 'environmental happiness': Infrastructuring environmental risk in oil and gas off shore operations. Science \& Technology Studies 29(1): 30-51.

Star SL (1999) The ethnography of infrastructure. American Behavioral Scientist 43(3): 377-391.

Star SL \& Bowker GC (2002) How to infrastructure? In: Lievrouw L A \& Livingstone S L (eds) The handbook of new media. Social shaping and consequences of ICTs. London: Sage Publications, 151-162.

Star SL \& Ruhleder K (1996) Steps toward an ecology of infrastructure: Borderlands of design and access for large information spaces. Information Systems Research 7(1): 111-134.

Wyatt S, Harris A \& Kelly SE (2016) Controversy goes online: Schizophrenia genetics on Wikipedia. Science \& Technology Studies 29(1): 13-29. 